EPiC Series in Engineering
Volume 3, 2018, Pages 1772-1777
HIC 2018. 13th International
Conference on Hydroinformatics

\title{
EvapoCalc: An Android Application to Estimate Evapotranspiration by Different Methods
}

\author{
Diogo Francisco Borba Rodrigues ${ }^{1}$, Geber Barbosa de Albuquerque Moura \\ ${ }^{2}$, Suzana Maria Gico Lima Montenegro', Tatiana Patrícia Nascimento da \\ Silva Rodrigues ${ }^{2}$, Leidjane Maria Maciel de Oliveira ${ }^{1}$, Ana Claudia Villar e \\ Luna Gusmão ${ }^{1}$, Diêgo Cézar dos Santos Araújo ${ }^{2}$
}

\author{
1 Federal University of Pernambuco, Recife 50670-901, Brazil \\ 2 Rural Federal University of Pernambuco, Recife 52171-900, Brazil \\ diogo.borbaregmail.com, gebermoura@icloud.com, \\ suzanam.ufpe@gmail.com, tatianapnsilva@hotmail.com, \\ leidjaneoliveira@hotmail.com, villareluna@yahoo.com.br, \\ villareluna@yahoo.com.br, diego@agro.eng.br
}

\begin{abstract}
The evapotranspiration consists of counting all the water on the surface of the earth lost to the atmosphere, through evaporation and transpiration. The evapotranspiration can be estimated from evaporimeters and lysimeters (direct methods) and empirical and semi-empirical models (indirect methods). Some models have been developed for semiarid regions such as the Blaney-Criddle and the Hargreaves-Samani, and other models for temperate climates, such as the Thornthwaite model. The Penman-Monteith model, recommended by the UN-FAO, is the most accurate estimating method for evapotranspiration. A determination of evapotranspiration is essential for irrigation management, to plan system and develop irrigation schedules. The present work aims to develop a tool for mobile devices to estimate evapotranspiration through models, with the help of a GPS receiver, and that allows the comparison of the different models with the FAO standard estimation method. The app is available on Google Play at https://play.google.com/store/apps/details?id=com.thunkable.android.diogo_borbar.Eva poCalc.
\end{abstract}


EvapoCalc: An Android Application to Estimate Evapotranspiration by ... D. F. B. Rodrigues et al.

\section{Introduction}

The reference evapotranspiration (ETo) is an essential agrometeorological variable for climatological and hydrological studies, as well as for irrigation planning and management, with an increasing requirement for information on the water needs of crops for the planning of projects at the regional scale (Moura, et al., 2013). There are a variety of methods for estimation of ETo, but their performance in different environments is diverse because they are empirical methods. The FAO Penman-Monteith (FAO PM) method is considered as a universal standard, and it considers many parameters related to the evapotranspiration process, such as net radiation(Rn), air temperature $(T)$, the vapor pressure deficit (De) and wind speed (U).

The use of the FAO PM equation is restricted because it requires numerous meteorological data that are not always available. This occurs mainly in developing countries where reliable climatic data sets of radiation, relative humidity, and wind speed are limited (Gocic \& Trajkovic, 2010). One of the alternatives to overcome this problem is presented by (Allen, Pereira, Raes, \& Smith, 1998) who recommended procedures to estimate the parameters of the FAO PM equation when some meteorological data are missing. The absence of meteorological data can also be overcome using ETo equations with fewer data requirements. (Allen, Pereira, Raes, \& Smith, 1998) proposed that in the absence of data for application of the FAO PM model, the Hargreaves-Samani equation can be used. However, this equation generally overestimates ET0 in humid places (Jensen, Burman, \& Allen, 1990).

It is verified, in most of works present in the literature, that the most studied methods are the Thornthwaite (TW), Hargreaves-Samani (HG), Blaney-Criddle (BC), Priestley-Taylor (PT), Turc (TC), Makkink (MK), Linacre (LN), Hamon, Jensen-Haise (JH) and Class A Tank (TCA). Different methods are developed or recommended for different climate conditions depending on the availability of local data, the precision required and time scale (Gonsaga, Alves, Lismar, \& Castro, 2011).

An information and communication technology (ICT) tool can provide farmers with information on land use and farm management, improving decision-making (Jordan, Eudoxie, Maharaj, Belfon, \& Bernard, 2016). Smartphones are getting more attention from the agricultural sector, and various applications are currently being developed to assist in daily activities, such as the applications developed by (Rodrigues \& Almeida, 2014) and (Delgado, Paredes, \& Martínez, 2015). The present work proposed the development of the EvapoCalc, and application that estimates evapotranspiration by different models. This application is recommended for researchers, irrigation managers, and farmers that can visualize and compare evapotranspiration estimated by different methods. The application also enables the determination of ETP in situ in a practical and fast way with the aid of the GPS sensor of the smartphone.

\section{Material and Methods}

The application was developed for the Android operating system, using the official Integrated Development Environment (IDE) from Google. Android Studio version 2.3.3, along with the Android SDK, comprised of an application development kit and smartphone emulators for testing. Application programming follows the MVC (Model-View-Controller) software architecture standard. Objectoriented application design allows simply adding additional functionality or implementing new 
EvapoCalc: An Android Application to Estimate Evapotranspiration by ... D. F. B. Rodrigues et al.

evapotranspiration methods. This application design facilitates the creation of transparent, reusable, and extensible code.

In the application, there have been implemented the evapotranspiration estimation models of Penman-Monteith (PM), Thornthwaite (TW), Linacre (LN), Hargreaves \& Samani (HG), BlaneyCriddle (BC), and Jensen-Haise (JH), presented in Equation 1, Equation 2, Equation 3, Equation 4, Equation 5, Equation 6 respectively.

\section{Equation 1}

$$
E T o_{P M}=\frac{0.408 \cdot s \cdot(R n-G)+\gamma \frac{900}{T+273} \cdot U_{2 m} \Delta e}{s+\gamma \cdot\left(1+0.34 \cdot U_{2 m}\right)}
$$

Equation 2

$$
\begin{array}{ll}
E T o_{T W}=16 \cdot(10 \mathrm{~T} / \mathrm{I})^{a} & \left(0 \leq \mathrm{Tm}<26.5^{\circ} \mathrm{C}\right) \\
E T o_{T W}=-415.85+32.24 \cdot T-0.43 \cdot T^{2} & \left(\mathrm{Tm} \geq 26.5^{\circ} \mathrm{C}\right)
\end{array}
$$

\section{Equation 3}

$$
E T o_{L N}=\frac{[500 \cdot(T+0.06 \cdot H) /(100-\phi)]+15 \cdot(T-T d)}{80-T}
$$

\section{Equation 4}

$$
E T o_{H S}=0.0023 \cdot Q o \cdot(T \max -T \min )^{0.5} \cdot(17.8+T)
$$

\section{Equation 5}

$$
E T o_{B C}=(0.457 T+8.13) \cdot p
$$

\section{Equation 6}

$$
E T o_{J H}=R_{s}(0.252 T+0.078)
$$

where $\mathrm{T}$ represents the mean air temperature $\left({ }^{\circ} \mathrm{C}\right), \mathrm{H}$ represents the altitude $(\mathrm{m}), \varphi$ symbolizes the latitude (degrees), $\mathrm{Td}$ refers to the dew point temperature $\left({ }^{\circ} \mathrm{C}\right), \mathrm{Rn}$ indicates the radiation balance (MJ 
EvapoCalc: An Android Application to Estimate Evapotranspiration by ... D. F. B. Rodrigues et al.

$\left.\mathrm{m}^{-2} \mathrm{~s}^{-1}\right), \mathrm{G}$ is the soil heat flux $\left(\mathrm{MJ} \mathrm{m}^{-2} \mathrm{~s}^{-1}\right)$, Rs is the global solar radiation $\left(\mathrm{mm} \mathrm{d}^{-1}\right), \gamma$ symbolizes the psychrometric constant, $\mathrm{U} 2 \mathrm{~m}$ represents the wind speed at $2 \mathrm{~m}$ height $\left(\mathrm{m} \mathrm{s}^{-1}\right), \mathrm{s}$ is the rate of change of the saturation vapor pressure $\left(\mathrm{kPa}^{\circ} \mathrm{C}^{-1}\right), \Delta \mathrm{e}$ indicates the difference between vapor saturation pressure and $\left(\mathrm{m} \mathrm{s}^{-1}\right)$, Tmax is the maximum temperature $\left({ }^{\circ} \mathrm{C}\right)$, Tmin is the minimum temperature $\left({ }^{\circ} \mathrm{C}\right)$, and $\mathrm{p}$ represents the percentage of total solar radiation (decimal), $\mathrm{I}$ is the temperature index, Qo is the daily extraterrestrial solar irradiance $\left(\mathrm{mm} \mathrm{day}^{-1}\right)$.

The user must provide at least temperature data to obtain evapotranspiration. Data on the date, latitude, longitude, altitude, maximum day length, number of days of the month, solar extraterrestrial radiation (for the Hargreaves \& Samani method) and daily light percentage (for the Blaney-Criddle method) are obtained with the aid of GPS sensor on the smartphone as shown in Figure 1.

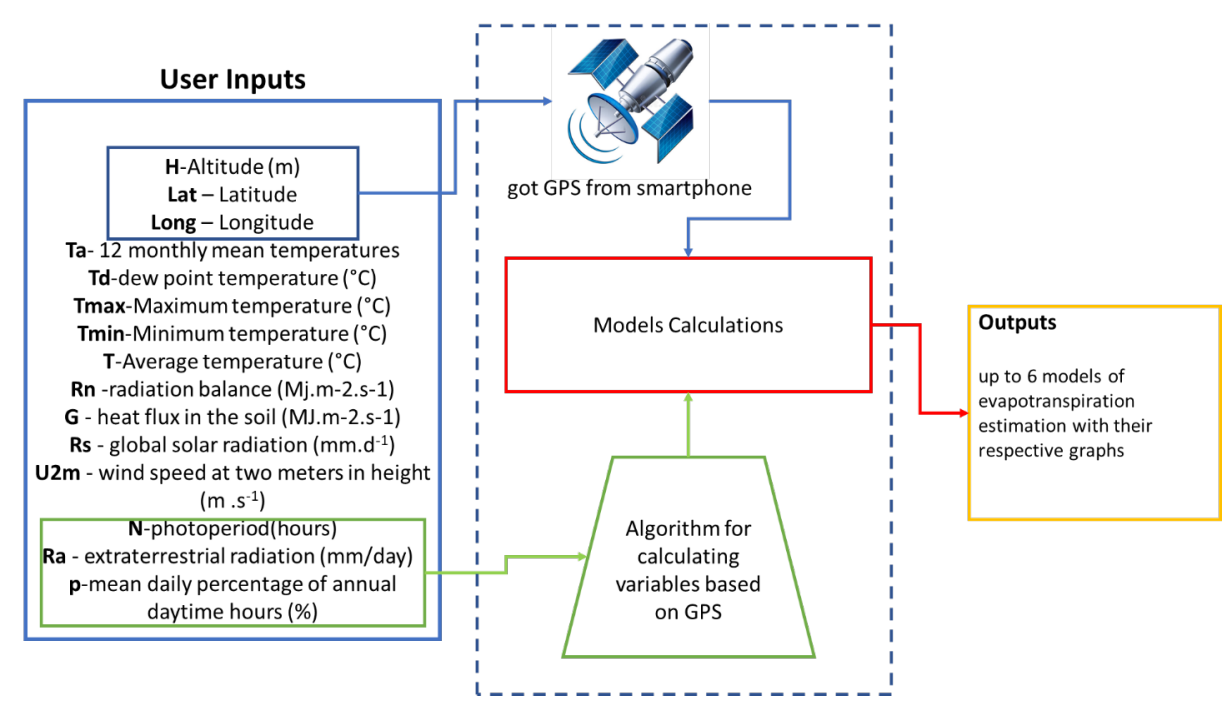

Figure 1: A schematic of the app model with inputs and outputs, the dashed line encompasses the app internal components.

Exception handling is designed to handle issues that occur during the execution of an order. It is an important feature of object-oriented languages that have been used in this application to provide a custom message that informs users on which component is not filled correctly. The built-in exception handling mechanism should improve application operation to prevent system crashes.

\section{Results and Discussion}

The application developed in this work is friendly and easy to use, giving farmers and technicians the ability to evaluate daily evapotranspiration useful for many water management tasks in agriculture. The application is designed to run only on devices running the Android operating system. Figure 2 represents the initial screen of the application in which the user can select the variables needed for evapotranspiration calculation. The next screen displays a form in which the user must fill in with the values of the parameters selected on the first screen, requesting help from the GPS sensor 
EvapoCalc: An Android Application to Estimate Evapotranspiration by ... D. F. B. Rodrigues et al.

and the smartphone date system to fill in some fields. The last screen provides numerical and graphical evapotranspiration values making it possible to compare methods of evapotranspiration determination with the standard FAO Penman-Monteith method.
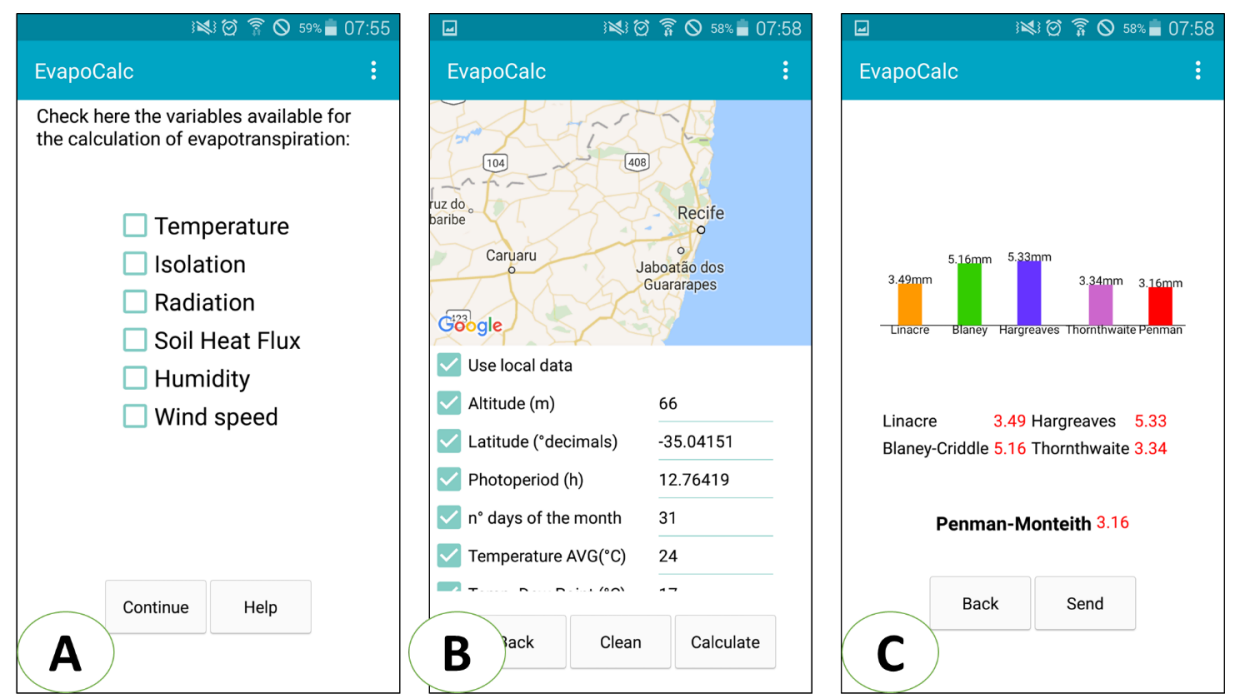

Figure 2: application screens: home screen(A); screen to enter data(B); screen with results(C)

Research conducted by (Migliaccio, Morganb, Fraissea, Vellidisc, \& Andreisa) identified that the application for irrigation management based on evapotranspiration resulted in water praise ranging from $42 \%$ to $57 \%$ when compared to slides based on an irrigation schedule (without considering rainfall). The availability of information such as evapotranspiration on smartphones is necessary for many tasks related to water management in agriculture: estimation of crop water needs, validation of data provided by agricultural climatic seasons, measurements of solar radiation at a site of interest to the installation of solar water heating systems, etc (Delgado, Paredes, \& Martínez, 2015).

\section{Conclusions}

In this paper, we present a mobile application that allows farmers and agricultural technicians to work with a smartphone to assist in the estimation of evapotranspiration. This variable is necessary for many tasks related to water management in agriculture, such as estimation of water needs of crops, validation of data provided by agricultural climate stations, among other tasks. This tool allows, with just a few clicks, to calculate evapotranspiration by six different methods, including FAO standard evapotranspiration. The application also provides graphics that facilitate the usability of the tool and allows sending of information not only by text message but also through other software, such as email applications or social networks. The application also allows the use of some wireless communication technologies for data transfer via Bluetooth. The application is a pioneer in estimating evapotranspiration by different methods directly from a smartphone. In future works the application will be able to connect to data of available meteorological stations online, facilitating the estimation of the evapotranspiration with the available data for the region. 
EvapoCalc: An Android Application to Estimate Evapotranspiration by ... D. F. B. Rodrigues et al.

\section{Acknowledgments}

The authors would like to thank the Coordination of Improvement of Higher Education Personnel (CAPES), the National Council for Scientific and Technological Development (CNPq) for the PQ and PDJ scholarships, as well as for funding research projects (Universal Call - MCTI / CNPq No. 14 / 2014, MCTI / CNPq / ANA No.23 / 2015 and FACEPE No.04/2017), Funding of Studies and Projects (FINEP), for the financing of the project REHIDRO 1830, to FACEPE / CAPES by PNPD scholarship.

\section{References}

Allen, R., Pereira, L., Raes, D., \& Smith, M. (1998). Crop evapotranspiration guidelines for computing crop water requirements. FAO Irrigation and Drainage Paper, 56.

Delgado, B., Paredes, M., \& Martínez, M. (2015). Software application for calculating solar radiation and equivalent evaporation in mobile devices. Agricultural Water Management, 151, pp. 3036. doi:http://dx.doi.org/10.1016/j.agwat.2014.09.012

Gocic, M., \& Trajkovic, S. (2010). Software for estimating reference evapotranspiration using limited weather data. Computers and Electronics in Agriculture, 79, pp. 158-162. doi:doi:10.1016/j.compag.2010.01.003

Gonsaga , L. d., Alves, G. R., Lismar, W. M., \& Castro, P. N. (2011). EVAPOTRANSPIRAÇÃO DE REFERÊNCIA: UMA ABORDAGEM ATUAL DE DIFERENTES MÉTODOS DE ESTIMATIVA. Pesquisa Agropecuária Tropical, n.3 41, pp. 456-465. doi:DOI: 10.5216/pat.v41i3.12760

Jensen, M. E., Burman, R. D., \& Allen, R. G. (1990). Evapotranspiration and irrigation water requirements. ASCE manuals and reports on engineering practice, 70.

Jordan, R., Eudoxie, G., Maharaj, K., Belfon, R., \& Bernard, M. (2016). AgriMaps: Improving sitespecific land management through mobile maps. Computers and Electronics in Agriculture, 123, pp. 292-296 . doi:http://dx.doi.org/10.1016/j.compag.2016.02.009

Migliaccio, K., Morganb, K., Fraissea, C., Vellidisc, G., \& Andreisa, J. (n.d.). Performance evaluation of urban turf irrigation smartphone app. Computers and Electronics in Agriculture, 118, pp. 136-142. doi:https://doi.org/10.1016/j.compag.2015.08.015

Moura, A. R., Montenegro, S. M., Antonino, A. C., Azevedo, J. R., Silva, B. B., \& Oliveira, L. M. (2013). EVAPOTRANSPIRAÇÃO DE REFERÊNCIA BASEADA EM MÉTODOS EMPÍRICOS EM BACIA EXPERIMENTAL NO ESTADO DE PERNAMBUCO BRASIL. Revista Brasileira de Meteorologia, 28, pp. 181-191. doi:http://dx.doi.org/10.1590/S0102-77862013000200007

Rodrigues, D. F., \& Almeida, C. D. (2014). THE IRRIGATION SCHEDULING IGDROID TOOL. Irriga, Edição Especial 01, pp. 21-28. doi:http://dx.doi.org/10.15809/irriga.2014v1n1p21 